\title{
Design and Development of A Multi Purpose Sanitizing Machine (UV-C Light Based)
}

\author{
Dr. N. P. Mungale ${ }^{1}$, Vikas Janbandhu ${ }^{2}$, Tanmay Tabhane ${ }^{3}$, Himanshu Giripunje ${ }^{4}$, Aditya \\ Pathak $^{5}$, Nikita Bhajipale ${ }^{6}$, Dheeraj Asare ${ }^{7}$, Sanket Waikar ${ }^{8}$ \\ ${ }^{1} H o D$, Department of Mechanical Engineering, ${ }^{2,3,4,5,6,7,8}$ Students \\ Dr. Babasaheb Ambedkar College of Engineering and Research, Nagpur, India, 441110
}

Received on: 08 May,2021

Revised on: 09 June,2021

Published on: 11 June,2021

\begin{abstract}
Due to COVID-19 pandemic, more than 112 million people infected globally and 2.47 million deaths reported worldwide. The World Health Organization (WHO) officially declared the COVID-19 outbreak is a Public Health Emergency of International Concern on January 30, 2020 and rapidly spread globally it also declared the global pandemic on March 11, 2020. Till now more than $156 \mathrm{~K}$ deaths have been recorded and 11 million people infected due to the virus as on 20th February 2021, and every passing day count of new cases is increased. The government of India (GoI) is taking lots of efforts to stop the spread and the government is also providing the vaccine but the availability of a vaccine is less and it will take a couple of months to be available in mass quantity. Now the government of India slowly opens all the public places with some guidelines and precautions like hand washing, wearing masks in public places, maintaining 2 to 3 fit distance between two people, good personal hygiene, and avoiding people gatherings. But still we are scared about the germs, bacteria or virus present on the material/object which we use daily. Therefore considering all this problem the efficient solution is, a multi purpose sanitizing machine is designed. The specialty of this machine is new innovative design consisting of a roller conveyor mechanism with cabinet like structure, in this machine $U V$-C light used for sanitization.
\end{abstract}

Keywords - COVID-19, WHO, GoI, Sanitizing machine, UV-C light.

\section{I- INTRODUCTION}

C oronavirus is a type of common virus that causes an infection in upper throat, nose, and sinuses. Most coronaviruses aren't dangerous. But severe acute respiratory syndrome coronavirus 2 (SARS-CoV-2) is a new type of coronavirus and it is very harmful and causing death, shortly called as COVID-19. The first case was identified in Wuhan, China, in December 2019. The disease has since spread worldwide, leading to an ongoing pandemic. Last year the World Health Organization (WHO) was declared a global health emergency on 11th March because of COVID-19 virus. The spreading rate of COVID-19 virus is rapidly increasing and it leads to lots of casualties/deaths every day globally. The coronavirus outbreak, which firstly detected in the central Hubei province of China in December, and the investigation is also made to find the exact source of virus. The scientists say that the coronavirus is originated from bats. This virus can be directly transmitted from person to person (infected person) and contaminated surface (by touching), there are several ways this can happen: Droplets or aerosols, Airborne transmission, Fecal-oral. Research shows that the COVID-19 virus can live in the air for up to 3 hours also it remain active on the surfaces for several days (depending on the material properties and texture of the contaminated surface the time period of virus may vary). The government of India (GoI) also takes lots of action and provides guidelines. 


\section{International Journal of Innovations in Engineering and Science, www.ijies.net}

For reducing the spread of COVID-19 virus strains. The vaccine is now available but not in mass quantities thus far, the government taking lots of efforts as well as special precautions like in some areas night curfew has been imposed and shutdown the school, college in some districts also implement the Janata curfew, Weekend curfew, etc. Also the government installed several sanitizing cabinets or tunnels in public places. Apart from this it is also important to disinfect the material which we are using on a daily basis. For example: books, currency, newspaper, vegetables, grocery, electronic gadgets like mobile phone, laptop, etc. For this purpose, lightweight, user-friendly, compact and low-cost devices play an important role in this situation. In this paper the suggested design/model of the sanitizing machine is a slight improvement over the existing ones because it makes combined use of roller conveyor and chamber along with UV-C (ultraviolet-C) light which effectively sanitizes the material/object. This device is not only effective against COVID-19 virus it also kills different harmful bacteria's.

\section{II- METHOLOGY}

How does UV-C light work?

Inside the UV light a small amount of mercury, either in a free state or embedded within the light tube's surface. When electricity is supplied to the light, this mercury is "excited" and emits UV rays.

Ultraviolet light is part of the electromagnetic spectrum, and it is classified into three different wavelength ranges:

[1] UV-A ranging from 315 to $400 \mathrm{~nm}$,

[2] UV-B ranging from 280 to $315 \mathrm{~nm}$ and

[3] UV-C ranging from 100 to $280 \mathrm{~nm}$

The UV-C wavelengths that range from $100 \mathrm{~nm}$ to 280 $\mathrm{nm}$ are germicidal properties. Ultraviolet (UV) light lies between X-rays and visible light, and it will be invisible to the human eye. The sun emits abundant amounts of light it also emits ultraviolet light but most of it is absorbed by the earth's ozone layer.

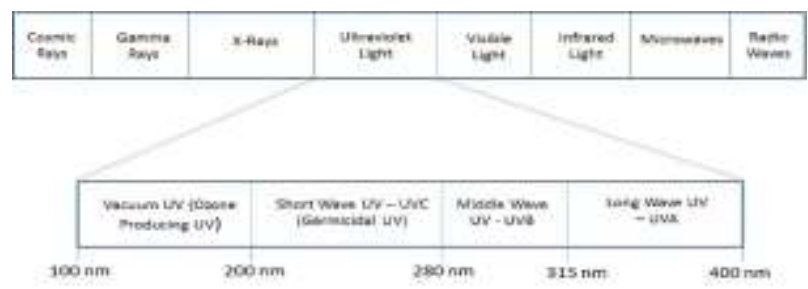

Design: It is a rectangular box type machine having two parts i.e. upper part and lower part. The upper parts are open on both sides (front and back) and between them roller conveyors are pleased, and feed provided to rollers by a small electric motor (DC motor). The lower part having cabinet-like structure, inside this we can place different objects (like mobile phone, book, currency, etc.), And inside these two parts there is one common UV-C lamp and two switches are provided for ON/OFF of the machine.

Working of the machine: the working is simple, firstly we have to placed the object inside the lower cabinet and close the door then switch ON the UV-C lamp and wait for 60 or 120 second for effective sanitization of the object (sanitization timing may vary object to object, maximum 5 minutes). Similarly we have to place the object on the roller conveyor (from front side opening) then switch ON the UV-C lamp as well as the motor and then wait until the object comes from back side opening.

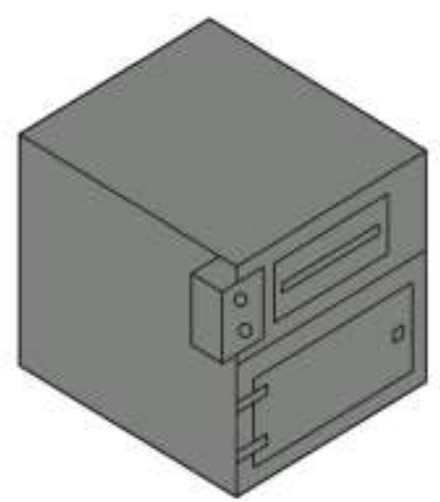

Fig 1-Schematic diagram of MPS machine

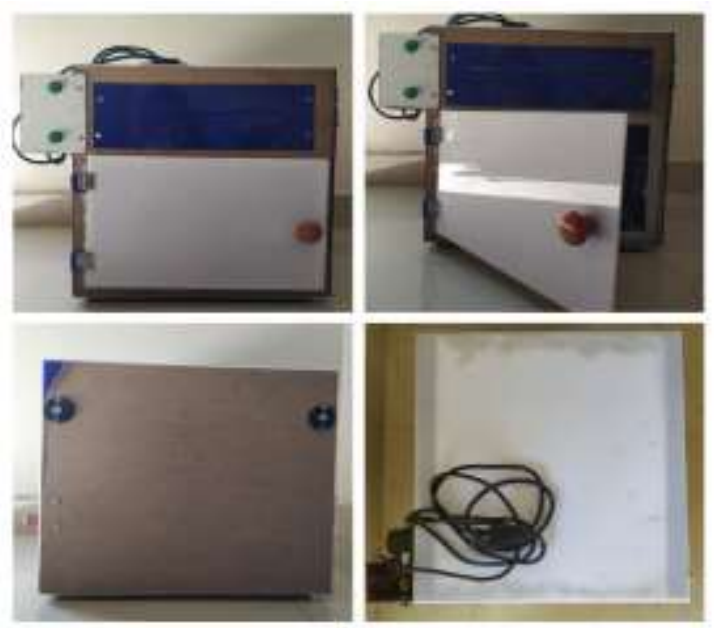

Fig 2- Schematic diagram of MPS machine after manufacturing 


\section{International Journal of Innovations in Engineering and Science, www.ijies.net}

Table: Specifications of Components:

\begin{tabular}{|c|c|c|c|}
\hline 8, no, & Camponents naane & Specificutions & Quantity \\
\hline 1 & UV-C (Uliraviolent-C) lightir & $\begin{array}{l}1215 \mathrm{~W} \text {, wavelictght } 222 \text { io } \\
254 \mathrm{~mm}\end{array}$ & $T$ \\
\hline 2 & Acrylic sheer & $6 \% 6$ fit, 3 mm thicknes & 1 \\
\hline 3 & DC motor & $12 \mathrm{VDC}, 10 \mathrm{in}, 50 \mathrm{~mm}$ & I \\
\hline 4 & Dlectric ballast & 2,90 to $240 \mathrm{~V}, 50 \mathrm{~Hz}$ & I \\
\hline 5 & Power supply module & $220 \mathrm{VAC}=12 \mathrm{VDC}$ & $t$ \\
\hline 6 & Roller cotrveyor & $20 \mathrm{~mm}$ in diameter. & I \\
\hline 7 & 3 Pin Power Cahle Mains Cond & 5 in 7 A. $250 \mathrm{~V}$ & $t$ \\
\hline 8 & Sinall hinge & $20 \cdot 20 \mathrm{tm}$ & 2 piese \\
\hline 9 . & Mapuetic droot catcher & Small & I \\
\hline 10 & ONOFF switch & Sraall push type & 2 \\
\hline
\end{tabular}

\section{III-DESCRIPTION AND NOVELTY}

This device will be the first of its kind of design. This sanitizing machine will be able to sanitize the surfaces of different objects like mobile phones, books, currency, etc. Ultraviolet sanitizing: UV-C light of wavelength $200-280 \mathrm{~nm}$ is used for this machine/device, Ultraviolet ray can cause cell fission, destroy the molecular structure of DNA or RNA, cause growing cells to die, achieve the effect of disinfection. Simple operation, effective sterilization in 5 minutes maximum. Roller conveyors take $60 \mathrm{sec}$ (paper sanitizing time is $60 \mathrm{sec}$.). $360^{\circ}$ Exposure (item will receive UVC light from all sides at a time) $99.99 \%$ Sterilization Rate. Safety switch: The built-in safety switch will automatically switch off the UV light when you open the door. Closing the door will resume sterilizing mode. Easy to use, work quickly, perfect for personal item sterilization. This enhanced sterilization UV light box can be used for laptops, office files, papers, currency, envelopes, Stationary items, food packets, keys, glasses, mobile devices and personal items.

\section{IV-APPLICATION}

As India gears up to back in normal state, it is very important to take more precautions against COVID-19 virus. From the last 11 to 12 months we all have been suffering from this pandemic. Hence, the use of such a type of sanitizing machine plays a very crucial role in every sector of our economy. This machine (multi purpose sanitizing machine) has been designed and fabricated/developed particularly for the following applications:

- Sanitization of the object/materials such as phone, watch, currency, document, groceries etc.
- It can be used in homes, retail shops, factories, offices etc.

\section{V- CONCLUSION}

This type of sanitizing machine is very effective against the COVID-19 virus, and because of its compact and lightweight design, the handling and installation (place like Home, office, hospital, malls, bank, etc.) of machines is very easy. It's simple design, easy to use and very effective against viruses. This all reasons make it comfortable to use in large quantities.

\section{REFERENCES}

[1] https://traninnovation.com/? gclid $=$ CjwKCAjwzvX7B RAeEiwAsXExo2jD47C49erygq7I5XKz3g2qnGIq6H EiRXXajkGGiOUOpH2iVtOBVRoCCmOQAvD_BwE

[2] https://www.orientelectric.com/homeappliances/health-appliances/uv-sanitech

[3] https://www.who.int/healthtopics/coronavirus\#tab=tab_1

[4] https://www.ncbi.nlm.nih.gov/pmc/articles/PMC5824 029/

[5] Far-UVC light (222 $\mathrm{nm})$ efficiently and safely inactivates airborne human coronaviruses.

[6] James Bolton, Christine Colton, The Ultraviolet Disinfection Handbook, American Water Works Association, 2008 ISBN 978158321584 5, pp. 3-4

[7] https://en.m.wikipedia.org/wiki/Ultraviolet_germicid al_irradiation

[8] Coronavirus disease (COVID-19) update (WHO) https://www.who.int/emergencies/diseases/novelcoronavirus-2019/question-and-answers-hub/q-adetail/coronavirus-disease-covid19\#: :text=symptom

[9] Coronavirus https://en.m.wikipedia.org/wiki/Coronavirus 